\title{
Psychological distress in relatives of critically ill patients: Risk and protective factors
}

Journal of Health Psychology

I-16

(C) The Author(s) 2018

Article reuse guidelines:

sagepub.com/journals-permissions

DOI: $10.1177 / 1359105318817357$

journals.sagepub.com/home/hpq

@SAGE

\section{Beatriz Gil-Juliál(i), M Desamparados Bernat-Adell2,3 (D), Eladio Joaquín Collado-Boira ${ }^{2}$, María Pilar Molés Julio ${ }^{2}$ and Rafael Ballester-Arnal ${ }^{2}$}

\begin{abstract}
The admission to an intensive care unit can result in a significant burden of emotional distress in the family. This study analyzes the psychological distress of 89 relatives of intensive care unit patients and the potential risk/protective factors for such distress. Families show high levels of anxiety, depression, and stress. Regarding risk factors, having steady partner, being a woman, and being a mother are associated with increased risk of anxiety, depression, and stress. Contrarily, being younger and having higher educational level are associated with reduced anxiety and stress. Influencing these trends could change positively the suffering course experienced by relatives and intensive care unit patients indirectly.
\end{abstract}

\section{Keywords}

critical health psychology, family, hospitalization, protective factors, psychological distress, risk factors

\section{Introduction}

The admission to an intensive care unit (ICU) of patients who are critically ill can result in a significant burden of emotional distress in the whole family (Vandall-Walker and Clark, 2011; Vandall-Walker et al., 2007), both in patients who not always have recalls of factual events and relatives who seem to live the whole event (Paul and Rattray, 2008).

It is important to note that the admission to these units is usually unexpected. Families are not normally emotionally prepared and most of times they have not much time to assimilate a new and unfamiliar situation given the little or no familiarity with these special circumstances. Moreover, the outcome raises many doubts and uncertainties about such significant issues, as the possible survival of the patient and/or the degree of disability of survival (Johansson et al., 2005; Mitchell et al., 2003; Wong et al., 2017) and a sense of unreality (Coulter, 1989). In this regard, the lives of relatives may be altered in many areas which could lead at best to a redistribution of roles in the family (Hupcey and Penrod, 2000; Van

\footnotetext{
'Universitat de València, Spain

2Universitat Jaume I de Castellón, Spain

${ }^{3}$ Hospital General Universitario de Castellón, Spain

\section{Corresponding author:}

Beatriz Gil-Juliá, Departamento de Personalidad, Evaluación y Tratamientos Psicológicos, Facultad de Psicología, Universitat de València, Av. Blasco lbáñez, 2I, 46010 Valencia, Spain.

Email: bgil@uji.es; beatriz.gil@uv.es
} 
Table I. Exclusion criteria.

(a) Aged below 18 years

(b) Being relative of a patient with an expected short stay in ICU or high probability of favorable medical outcomes. This implies to exclude those relatives whose patients are admitted only for postoperative control after scheduled high-risk interventions, with an ICU stay below 48 hours

(c) Cognitive impairment that makes difficult to answer the study questions properly

(d) Do not understand the Spanish language

(e) Relatives with a psychological disorder diagnosed recently that could interfere the assessment and mask the possible psychological effects derived from the income in the ICU of their loved one

ICU: intensive care unit.

Horn and Tesh, 2000) and sometimes to overloading the role of the caregiver.

All this may contribute to triggering a wide variety of emotional symptoms in relatives (Hughes et al., 2005; McAdam and Puntillo, 2009; Verhaeghe et al., 2005) which could affect their own wellbeing and the wellbeing of patients indirectly, derived from the lack of proper support provided by the relative given his or her emotional turmoil and the stress experienced. Moreover, relatives may defer their needs in favor of the patient's wellbeing (Hinkle and Fitzpatrick, 2011). Most family caregivers may pay less attention to their own health needs than to the patient's, a situation that can influence the caregivers' health and their ability to provide support (Choi et al., 2013). As a result, addressing psychological distress of relatives must also be an integral part of a comprehensive critical care approach; it is especially important to take into account those factors which may facilitate, or protect from, experiencing diverse psychological symptoms.

The aim of this study is to analyze the psychological distress of relatives of critically ill patients during the period of admission to the ICU in terms of anxiety, depression, subjective perception, stress, and degree of interference caused by ICU admission, as well as the possible differences or correlations in terms of sociodemographic variables. Similarly, the second goal of this study is to identify potential risk and protective factors for the psychological distress of relatives.

\section{Materials and methods}

We present here a descriptive study of the psychological distress of relatives of critically ill patients which was conducted in a polyvalent ICU located at the University General Hospital of Castellón (Spain).

\section{Participants}

Initially, our aim was to include all the relatives of those patients admitted to the ICU during the period of 1 year but the exclusion criteria (Table 1) reduced considerably the total sample.

From consecutive admissions during the period in which the research was conducted and taking into account different factors, such as the mortality rate, the voluntariness, and the transfer to another ward or hospital, and the exclusion criteria cited above, a total of 89 relatives of critically ill patients were included in the study (Figure 1). The mean age was 46.31 (standard deviation $(\mathrm{SD})=15.29$ ) years. Table 2 shows the main demographic and clinical characteristics of the final sample.

\section{Data collection}

After the approval by the Clinical Research Ethics Committee of the Hospital and in order to identify those relatives of critically ill patients who were approved to participate in the study, a psychologist of the research team contacted them when they were informed or visiting the patient as soon as possible after their admission to the ICU. 


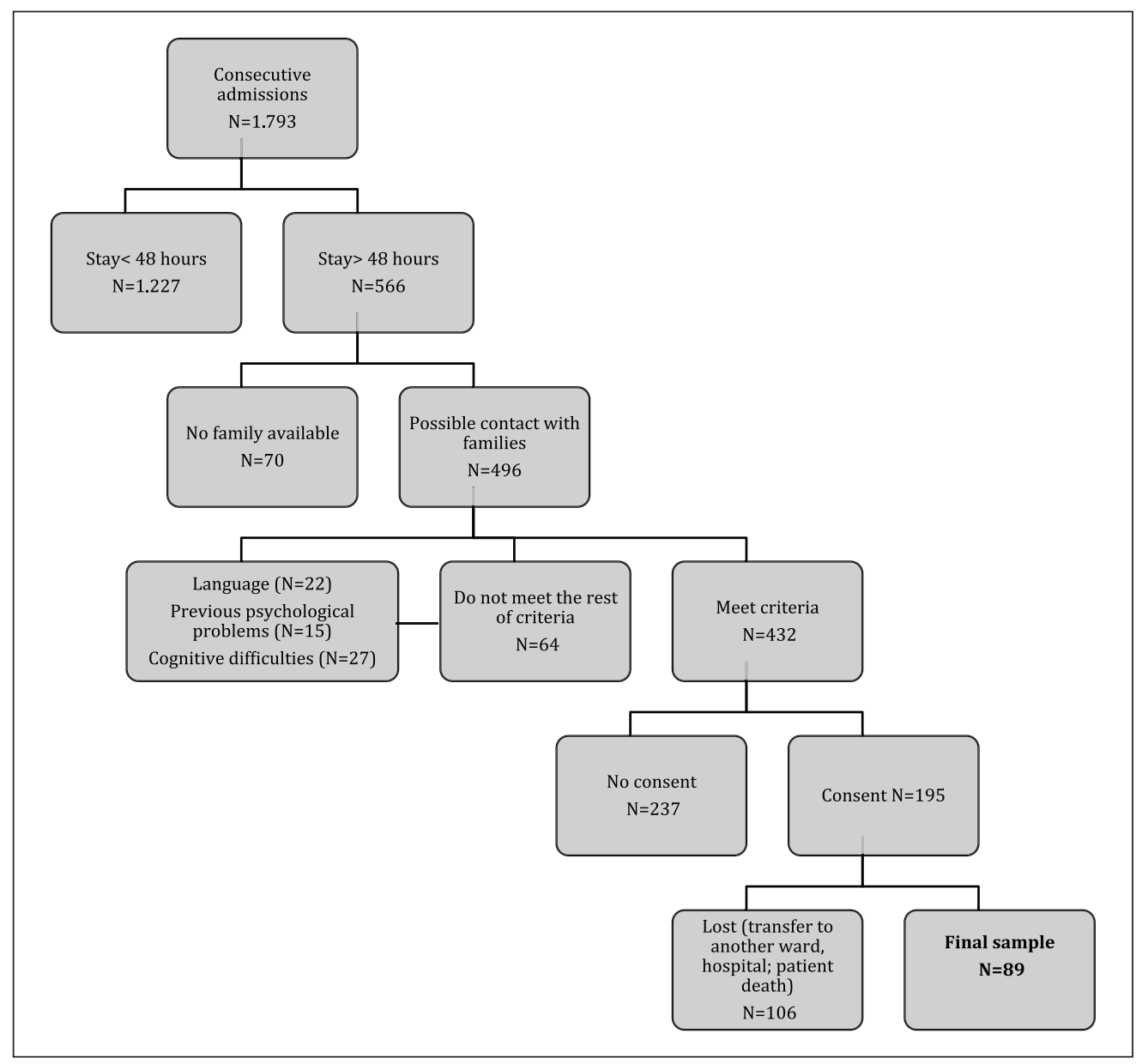

Figure I. Final sample of relatives.

All potential participants were informed about the objectives, characteristics of the study, the voluntary participation, anonymity, and confidentiality of the data collected. It was necessary to obtain informed consent to carry out the assessment. After confirming that relatives met criteria for inclusion in the study, the psychological evaluation was done by a psychologist specially trained in this area. The time spent on each evaluation was 60-90 minutes trying to complete it in a single session. When it was not possible, the assessment was concluded the following day.

The study has been performed in accordance with the ethical standards laid down in the 1964 Declaration of Helsinki and its later amendments.

\section{Instruments}

Data related to demographic characteristics were collected in a record sheet. It included age, gender, marital status, have or not having offspring, educational level, kinship with patient, and place of residence.

The following instruments were administered to relatives:

- The Hospital Anxiety and Depression Scale (HADS; Zigmond and Snaith, 1983 ) is a screening questionnaire used to measure anxiety ( 7 items) and depression (7 items). It has a 4-point (0-3) scale for 
Table 2. Demographic characteristics of total study sample.

\begin{tabular}{|c|c|c|c|}
\hline \multirow[t]{2}{*}{ Demographics } & \multicolumn{3}{|l|}{ Relatives $(N=89)$} \\
\hline & & Mean & SD \\
\hline \multirow[t]{2}{*}{ Age (years) } & & 46.31 & 15.29 \\
\hline & & $N$ & $\%$ \\
\hline \multirow[t]{2}{*}{ Gender } & Male & 24 & 27 \\
\hline & Female & 65 & 73 \\
\hline \multirow[t]{4}{*}{ Educational level } & No studies & 3 & 3.7 \\
\hline & Primary school & 43 & 52.4 \\
\hline & High school & 20 & 24.4 \\
\hline & University & 16 & 29.5 \\
\hline \multirow[t]{2}{*}{ Marital status } & Married/living with couple & 61 & 72.6 \\
\hline & Single & 23 & 27.4 \\
\hline \multirow[t]{2}{*}{ Offspring } & Yes & 49 & 75.4 \\
\hline & No & 16 & 24.6 \\
\hline \multirow{5}{*}{ Kinship } & Partner & 34 & 40 \\
\hline & Son/daughter & 32 & 37.6 \\
\hline & Siblings & 5 & 5.9 \\
\hline & Father/mother & 11 & 13 \\
\hline & Another family member & 3 & 3.5 \\
\hline \multirow[t]{4}{*}{ Place of residence } & Castellón city & 39 & 55.7 \\
\hline & Castellón province & 27 & 38.6 \\
\hline & Rest of Spain & 3 & 4.3 \\
\hline & Abroad & I & I.4 \\
\hline
\end{tabular}

SD: standard deviation.

each item (range: 0-21). Scores between 8 and 10 indicate a possible clinical disorder; scores $\geqslant 11$ indicate a probable clinical disorder. This questionnaire has established a good reliability and validity (Herrero et al., 2003; Quintana et al., 2003; Tejero et al., 1986; Terol et al., 2007; Zigmond and Snaith, 1983).

- The State-Trait Anxiety Inventory (STAI; Spielberger et al., 1983) is based on a 4-point Likert-type scale and consists of 20 items for assessing trait anxiety and 20 for state anxiety. The scores range between 0 and 60 in each scale and higher scores indicate greater anxiety. In its original studies, the internal consistency range from 0.83 to 0.92 and the test-retest reliability coefficient obtained by Spielberger et al. (1983) was also high $(r=0.81)$.
- The Beck Depression Inventory (BDI; Beck et al., 1961) is a 21-item measure of symptoms and attitudes related to cognitive, behavioral, affective, and somatic components of depression consisting of four statements rated from 0 to 3 in terms of severity. Cut-off scores are used to evaluate the subject's responses. A total score $<10$ : no or minimal depression, 10-18: mild depression, 19-29: moderate depression, and $>30$ : severe depression (Beck et al., 1988). It has well-established psychometric properties (Beck et al., 1988; Lasa et al., 2000; Sanz and Vázquez, 1998).

- The Mood Scale was developed by the ICU psychologists in order to assess easily the patient's subjective perception of mood. It consists of three items that are 
answered following a visual analog scale ranging from 0 to 10 , which assesses general psychological distress, anxiety, and depressed mood. In this study, its internal consistency (Cronbach's alpha) is 0.782 .

- The ICU Stressors Scale is an adaptation to the context of ICU of the Hospital Stressors Scale developed by Richart et al. (1993). The adaptation includes the original scale items as well as new ones from the literature reviewed (López et al., 1990; Volicer and Bohanon, 1975) and the clinical experience of ICU professionals, in order to assess the degree of stress generated by various factors associated with ICU. The questionnaire consists of 40 items and the responses are scored according to a 5-point Likert-type scale. This adaptation presents a satisfactory reliability assessed through internal consistency (Cronbach's alpha) of 0.951.

- The Inadaptation Scale (Echeburúa and Corral, 1987) reflects the extent to which the relatives' current problems affect different areas of daily life: work/studies, social life, free time, relationship with partner, and family life. This instrument has a subscale that takes account of the overall level of maladjustment in everyday life given the particular situation experienced by participants. It comprises a total of 6 items, scored between 0 and 5 in accordance with a Likert-type scale. The full range of the instrument is $0-30$. The overall cut-off point is 12 and 2 for each area. The higher the score, the greater the level of inadaptation. Its psychometric properties (Echeburúa et al., 2000) show test-retest reliability of 0.86 and internal consistency alpha coefficient of 0.94 . In this study, the internal consistency is 0.763 .

\section{Statistical analysis}

All statistical analyses were performed using SPSS 23.0. To describe the basic characteristics of the sample, descriptive and frequency analyses were used, including both sociodemographic variables and others related to the emotional distress of relatives.

A one-sample $t$-test was considered in order to compare our anxiety and depression results with those obtained by other populations. The magnitude of the differences in these contrasts was estimated by calculating the effect size, specifically, through Cohen's $d$. Effect sizes around .20 were considered small, around .50 moderate, and close to .80 large (Cohen, 1988).

Similarly, we studied the relationship between different sociodemographic variables with the psychological distress of family members in terms of anxiety, depression, subjective perception of distress, levels of stress, and degree of interference caused by ICU admission. For this purpose, Pearson's and Spearman's correlation coefficients (depending on the variables' type), Student's $t$-test, and the KruskalWallis test (reduced sample size) were used. Finally, a multiple linear regression analysis was performed to explore which variable had more influence on the emotional distress of the relatives. The reference categories for the dummy variables were as follows: man (for gender), no steady partner (for to have or not a steady partner), to be the partner (for kinship with patient), and living in Castellón city (for place of residence). The statistical significance was given by a $p$-value $\leqslant .05$.

\section{Results}

\section{Descriptive results}

Related to anxiety symptoms, the mean score of patients' family members assessed by HADS is $13.24(\mathrm{SD}=4.26)$. 76.4 percent of relatives show a mean score indicative of the presence of anxiety disorder. The rest of the scores of relatives would be just suggestive of the presence of the disorder $(12.4 \%)$ or would be in the normal range $(11.2 \%)$. Regarding the state anxiety and trait anxiety (STAI), the mean scores are $36.36(\mathrm{SD}=12.66)$ and $22.92(\mathrm{SD}=10.31)$, respectively. According to this scale, the state anxiety mean would correspond to the 89 
Table 3. Anxiety and depression mean scores compared to the scores obtained in other populations.

\begin{tabular}{|c|c|c|c|c|c|c|c|}
\hline & \multicolumn{3}{|c|}{ General population ${ }^{\mathrm{a}}$} & \multicolumn{2}{|c|}{$\begin{array}{l}\text { Internal medicine } \\
\text { inpatients }{ }^{\mathrm{b}}\end{array}$} & \multicolumn{2}{|c|}{$\begin{array}{l}\text { ICU primary } \\
\text { decision-maker } \\
\text { relative }^{c}\end{array}$} \\
\hline & $M(S D)$ & $M(S D)$ & $t$ & $M(S D)$ & $t$ & $M(S D)$ & $t$ \\
\hline HADS-Anxiety & I 3.24 (4.25) & $5.1(3.7)$ & $18.03 * * * *$ & $5.2(4.2)$ & $|7.8|^{* * * *}$ & $10(4)$ & $7.17 * * *$ \\
\hline HADS-Depression & I I.48 (4.65) & $3.9(3.1)$ & $15.39 * * *$ & $7.3(4.7)$ & $8.49 * * *$ & $7(4)$ & $9.09 * * *$ \\
\hline
\end{tabular}

ICU: intensive care unit; SD: standard deviation; HADS: Hospital Anxiety and Depression Scale.

aGeneral population (Michopoulos et al., 2008).

bInpatients in the Internal Medicine Department (Michopoulos et al., 2008).

ICU relatives identified as primary decision maker (Anderson et al., 2008).

$* * * p<.001$.

percentile for men and 85 for women. And the trait anxiety mean would correspond to the 65 percentile for men and 45 for women.

In terms of depression symptoms, the HADS shows a mean score of $11.48(\mathrm{SD}=4.65)$. The majority of relatives $(59.6 \%)$ show a mean score indicative of the presence of depressive disorder, 16.9 percent suggestive of the disorder, and the 23.6 percent would be in the normal range. In accordance with BDI, results show that the relatives' mean score is 16.60 $(\mathrm{SD}=8.54)$ what is considered mild depression. In terms of percentages, these results show absence of depression in 20 percent, mild depression in 37.5 percent, moderate depression in 35 percent, and major depression in 7.5 percent of relatives.

As it is shown in Table 3, anxiety and depression means assessed by HADS differ from the mean scores obtained in other studies' samples (Anderson et al., 2008; Michopoulos et al., 2008). Regarding anxiety, our mean score was significantly higher than those obtained in general population $(t=18.03 ; p<.001 ; d=2.04)$, internal medicine inpatients $(t=17.81 ; p<.001$; $d=1.90$ ), and other ICU relatives although in this case they were identified as primary decision maker $(t=7.17 ; p<.001 ; d=0.78)$. In this same line, the depression mean score was also significantly higher than the mean obtained in general population $(t=15.39 ; p<.001 ; d=1.91)$, internal medicine inpatients $(t=8.49 ; p<.001 ; d=0.89)$, and ICU relatives $(t=9.09 ; p<.001 ; d=1.03)$
(Table 3). In all of the cases, the effect size was considered large.

Related to the relatives' subjective perception of emotional distress (range: $0-10$ ), the general perception mean scores of distress $(\mathrm{M}=6.41 ; \mathrm{SD}=2.57)$ and depressive mood $(\mathrm{M}=6.43 ; \mathrm{SD}=2.86)$ are very similar and slightly lower than the anxiety subjective perception $(\mathrm{M}=7.07 ; \mathrm{SD}=2.25)$.

Another important issue is the stress level perceived by relatives of ICU patients. Results show an overall stress level of $3.03(\mathrm{SD}=1.03)$ scored between 0 and 4 . In terms of percentages, the situation of having a loved one admitted to an ICU has generated a great deal (40.5\%) and a lot of (33.8\%) stress in relatives. Some of the most important stressors for relatives are "thinking that something serious can happen to patient" (91.8\%), "patient may die" (85\%), and the fact that "the admission to the ICU is unexpected" (75.7\%) (Table 4 shows the 10 stressors with highest mean scores). Conversely, other factors have been considered as non-stressful at all by an important percentage of relatives (Table 5). For instance, "having too many visiting hours" $(81.4 \%)$, "thinking that the patient is cared for by unfamiliar health professionals" (76.4\%), and "eating at different times to go and see your loved one" (75.7\%).

Regarding the degree of interference caused by the patient's ICU admission, results show an overall interference of $3.84(\mathrm{SD}=1.18)$ scored between 0 and 5 . Analyzing the different areas of 
Table 4. The most important stressors for relatives of ICU patients.

- Something serious can happen to patient

- Patient may die

- Unexpected admission to the ICU

- Thinking that the patient does not get pain relief even with medication

- Thinking about possible sequelae that prevent the patient to return to normal life

- Patient is in pain

- The stress caused by the uncertainty associated with surgery

- Being separated from the patient

- The patient may reveal fear

- Not knowing what the disease is

$60.3 \%$

ICU: intensive care unit.

Table 5. Factors considered as non-stressful at all by relatives of ICU patients.

- Having too many visiting hours

- Patient is cared for by unfamiliar health professionals

- Eating at different times to go and see your loved one

- Thinking of the possible loss of money caused by the disease

- Seeing other seriously ill patients in the ward

- Hours of visits

- Thinking that the time information is insufficient

ICU: intensive care unit.

daily life, ordered by the degree of interference, relatives state that this situation has great interference on their free time $(60 \%)$, work/studies $(41.2 \%)$, social life $(37.5 \%)$, family life $(35 \%)$, and the relationship with partner (31.1\%).

\section{Modulating role of sociodemographic variables on the psychological distress}

Analyzing the influence of certain demographic variables, such as the gender, on anxiety, depression, and subjective perception of emotional distress, results show statistically significant differences in depression $(t=-3.04 ; p=.003)$ and almost significant in anxiety $(t=-1.98 ; p=.051)$ both of them assessed by HADS. The rest of mean scores, although not statistically significant, are higher in women. Related to general stress, no statistically significant differences have been found by gender $(t=-1.16 ; p=.248)$. However, significant differences have been found in the stress caused by different factors: patient is in pain $(t=-2.14 ; p=.036)$ or may be in pain because of surgery/tests $(t=-2.16 ; p=.034)$; the stress caused by the uncertainty associated with surgery $(t=-2.58 ; p=.012)$; feeling that health professionals are in too much of a hurry $(t=-2.08 ; p=.041)$; and feeling strange smells $(t=-2.03 ; p=.046)$. All these mean scores are higher in women. In relation to the degree of interference caused by the patient's ICU admission, statistically significant differences have been shown in social life when women are more affected $(t=-2.06 ; p=.043)$.

Regarding the marital status (having or not a steady partner), results show higher mean scores in anxiety (HADS; State/Trait-STAI), depression (HADS; BDI), and subjective perception of emotional distress, in relatives with partner. The differences are statistically significant in anxiety (HADS; $t=-2.57 ; p=.012$ ). Similarly, significant differences have also been 
found in the stress caused by the uncertainty associated with surgery $(t=-1.99 ; p=.050)$. When it comes to the degree of interference caused by the patient's ICU admission, no statistically significant differences have been revealed.

Analyzing the differences by have or not having offspring, statistical differences have been found in depression assessed by HADS $(t=-2.66 ; p=.010)$. Similarly, differences are significant in the stress caused by having unknown health professionals caring for the patient $(t=2.59 ; p=.013)$ and believing that the information time is insufficient $(t=2.39$; $p=.021)$. These two factors are more stressful for relatives with no offspring. Related to the degree of interference caused by ICU admission, no statistically significant differences have been found in any of the areas.

According to kinship with patient, the Kruskal-Wallis test shows no statistically significant differences in anxiety, depression (BDI), and subjective perception of emotional distress, whereas these differences are significant in depression assessed by HADS $\left(\chi^{2}=18.14\right.$; $p=.003)$. In relation to stress, differences have not been significant in general stress $\left(\chi^{2}=8.69\right.$; $p=.122)$, while they have been statistically significant in factors related to the pain suffered by the patient $\left(\chi^{2}=9.86 ; p=.043\right)$. Related to the degree of interference caused by ICU admission, significant differences have been found in work/ studies $\left(\chi^{2}=13.46 ; \quad p=.019\right)$, social life $\left(\chi^{2}=16.62 ; p=.005\right)$, free time $\left(\chi^{2}=14.49\right.$; $p=.013)$, relationship with partner $\left(\chi^{2}=15.84\right.$; $p=.007)$, and life in general $\left(\chi^{2}=21.54 ; p=.001\right)$.

When examining the influence of the place of residence (Castellón city and Castellón provincelor out of the city), relatives who are not living in the city show higher mean scores in anxiety, depression, and subjective perception of emotional distress although these differences have been statistically significant in state anxiety (STAI; $t=-2.18 ; p=.043)$, depression assessed by BDI $(t=-2.99 ; p=.008)$, and general perception of emotional distress $(t=-2.59$; $p=.012$ ). Related to the stress level, statistically significant differences have not been found in general stress but in the stress caused by other factors, with higher mean scores in relatives living out of the city. Those factors are shown in Table 6. In relation to the degree of interference of ICU admission, no statistically significant differences have been found.

When analyzing possible correlations between the relatives' age and anxiety, depression, and subjective perception of emotional distress, correlations are only statistically significant in depression assessed by HADS $(r=0.34 ; p=.001)$. Results also show that the relation between the age and general stress is not statistically significant. However, significant negative correlations have been found between age and different stressors: not knowing test/treatment results $(r=-0.39 ; p=.002)$, organizing to attend visits $(r=-0.25 ; p=.042)$, not knowing when things will be done to the patient $(r=-0.26 ; p=.037)$, the patient is not receiving medication for pain relief when he or she needs it ( $r=-0.27 ; p=.032)$, the patient is attended by different doctors during the stay $(r=-0.25 ; p=.037)$, and being informed by different doctors $(r=-0.29 ; p=.012)$. In this sense, as relatives become older, these factors generate less stress. There is no lineal correlation at all between age and some stressors (e.g. patient may die $(r=0.00 ; p=.988)$, visiting hours $(r=0.00 ; p=.964)$, and traveling daily to visit the patient in four opening hours $(r=0.00$; $p=.968$ ). Regarding the interference caused by ICU admission, there is no significant correlation with age.

The relation between educational level and anxiety and depression is shown in Table 7. Results show a significant negative correlation with state-anxiety (STAI; $r=-0.45 ; p=.009$ ), depression assessed by HADS $(r=-0.38$; $p=.000)$, and by BDI $(r=-0.49 ; p=.004)$, as well as with subjective perception of depression $(r=-0.30 ; p=.007)$. In this sense, as educational level increases, anxiety, depression, and subjective perception of depression decrease. Related to the stress, no significant correlation has been found with general stress though the correlation is statistically significant and negative with one stress factor: believing that 
Table 6. Differences by place of residence in ICU relatives' stressors (only statistically significant differences).

\begin{tabular}{lll}
\hline & $t$ & $\begin{array}{l}\text { Significant } \\
p \leqslant .050\end{array}$ \\
\hline - Not being able to take care of family as usual & -2.44 & .018 \\
- The uncertainty associated with surgery & -2.06 & .045 \\
- Not knowing when the patient will be discharged from ICU & -2.54 & .014 \\
- Thinking about patient could be in pain because of surgery/tests & -2.28 & .027 \\
- The hospital is far from home & -2.21 & .032 \\
- Sleeping out of home & -3.52 & .001 \\
- Not being with the patient & -3 & .004 \\
- Traveling daily to visit the patient in the four opening hours & -3.57 & .001 \\
- The way in which the visiting hours are arranged & -2.94 & .005 \\
- The patient has to remain isolated by prescription & -2.47 & .018 \\
\hline
\end{tabular}

ICU: intensive care unit.

Table 7. Spearman's correlations between level of studies and anxiety-depression symptoms and subjective perception of mood.

\begin{tabular}{lc}
\hline & Level of studies \\
\hline Total HADS-Anxiety & -0.21 \\
Total HADS-Depression & $-0.38^{* * *}$ \\
STAI-State & $-0.45^{* *}$ \\
STAI-Trait & -0.21 \\
BDI & $-0.49^{* *}$ \\
EAI-general distress subjective perception & -0.04 \\
EA2-anxiety subjective perception & -0.12 \\
EA3-depressive subjective perception & $-0.30^{* *}$ \\
\hline
\end{tabular}

HADS: Hospital Anxiety and Depression Scale; STAI: State-Trait Anxiety Inventory; BDI: Beck Depression Inventory. $*_{p}<.05 ; * * p<.01 ; * * *_{p}<.00 \mathrm{I}$.

something serious can happen to patient $(r=$ $-0.25 ; p=.044)$. Related to the interference caused by ICU admission, there is no significant correlation.

Finally, in order to find potential predictors for psychological distress in relatives of ICU patients, a multiple linear regression analysis was performed with sociodemographic variables as independent variables (age, gender, educational level, having or not steady partner, kinship with patient, and place of residence) and anxiety, depression, and total stress level scores as dependent variables. In relation to anxiety and depression scores, and in order to simplify the results, we took into account the
HADS scores given the correlation found among the different measures included in the study. Table 8 shows the results related to the multiple linear regression analysis.

Regarding anxiety, results show that all the abovementioned independent variables explain 30.7 percent of the variance $(p=.010)$. Particularly, having steady partner is associated with increased risk of experiencing anxiety $(p=.024)$. By contrast, being younger $(p=.045)$, having a higher educational level $(p=.016)$, and being the patient's son $(p=.027)$ are associated with reduced anxiety symptomatology.

Results related to depression symptoms reveal that all independent variables explain the 
37.4 percent of the variance $(p=.001)$. Specifically, being woman could be considered as a risk factor to the extent that it is associated with increased depression symptomatology $(p=.019)$. On the contrary, having a higher educational level $(p=.014)$ and being the patient's son $(p=.013)$ seem to protect because they are associated with lowered depression levels.

In relation to the total stress experienced by relatives, and including all the independent variables, the results show a model which explains the 68.7 percent of the variance $(p=.004)$. In this regard, being the patient's mother is considerably associated with the increased total stress experience $(p=.013)$. However, other variables are associated with reduced stress experience, such as being younger $(p=.008)$, having higher educational level $(p=.041)$, and particularly being other relative $(p=.000)$.

\section{Discussion}

Our study reveals significant information about the psychological impact of intensive care experience on relatives. Families of ICU patients show high levels of anxiety and depression symptoms as other authors have also stated (Kao et al., 2016; Turner-Cobb et al., 2016). 76.4 percent of relatives have clinical anxiety, symptoms in line with other studies (Fumis and Deheinzelin, 2009; Pochard et al., 2001, 2005) and higher than others (Anderson et al., 2009; Fumis et al., 2015a, 2015b; Hwang et al., 2014) considering that the conditions of these last studies were not exactly the same (e.g. data were collected at time of patient discharge and in an open visiting policy ICU). Similarly, the prevalence for stateanxiety symptoms is 81.5 percent for women and 58.3 percent for men, similar to the data obtained in a preliminary study (Gil et al., 2009). Related to depression, the prevalence is 59.6 percent for HADS and 42.5 percent for BDIthe latter percentage includes relatives with moderate (35\%) and severe depression (7.5\%). Our prevalence for depression is higher than the prevalence found in other studies (Anderson et al., 2009; Fumis et al., 2015b; GómezCarretero et al., 2009; Maruiti et al., 2008) and similar/slightly higher than the prevalence obtained by other authors (Carlson et al., 2015; Pochard et al., 2001, 2005). Differences in the prevalence of depression symptoms may be due in part to variables associated with the medical situation or patients' severity. In fact, some studies with lower prevalence of depression included relatives of patients admitted only for postoperative control, one of our exclusion criteria. Similarly, it is worth mentioning that the ICU relatives' psychological distress in terms of anxiety and depression is higher than the anxiety and depression obtained in other populations, such as general population and inpatients of an internal medicine department (Michopoulos et al., 2008), as well as the symptomatology showed by other ICU relatives (Anderson et al., 2008). All this highlights the emotional turmoil experienced by family members in ICU. These last differences could be explained by some particular characteristics of these relatives, for example, the fact that they were the primary decision maker.

Related to the relatives' subjective perception of distress, we found higher scores on anxiety subjective perception than on depression and general distress perception. Moreover, self-reported mood was consistent with the actual psychological distress assessed previously. Comparing these results has not been possible because of the lack of studies on the subjective perception of emotional distress of ICU relatives.

In addition, differences in anxiety and depression by demographic variables such as the gender, marital status, kinship, place of residence, age, and educational level have been found. By gender, women have statistically significant higher level of depression symptoms. By marital status, relatives with partner have more anxiety. Differences by kinship have also been found although only statistically significant in depression. Mothers and partners show higher depression scores which is well understood if we consider the different losses experienced by the spouse (Stroebe et al., 2008; Zisook and Shuchter, 1991) and mothers (Leahy, 1992; Wijngaards-de Meij et al., 2008) 


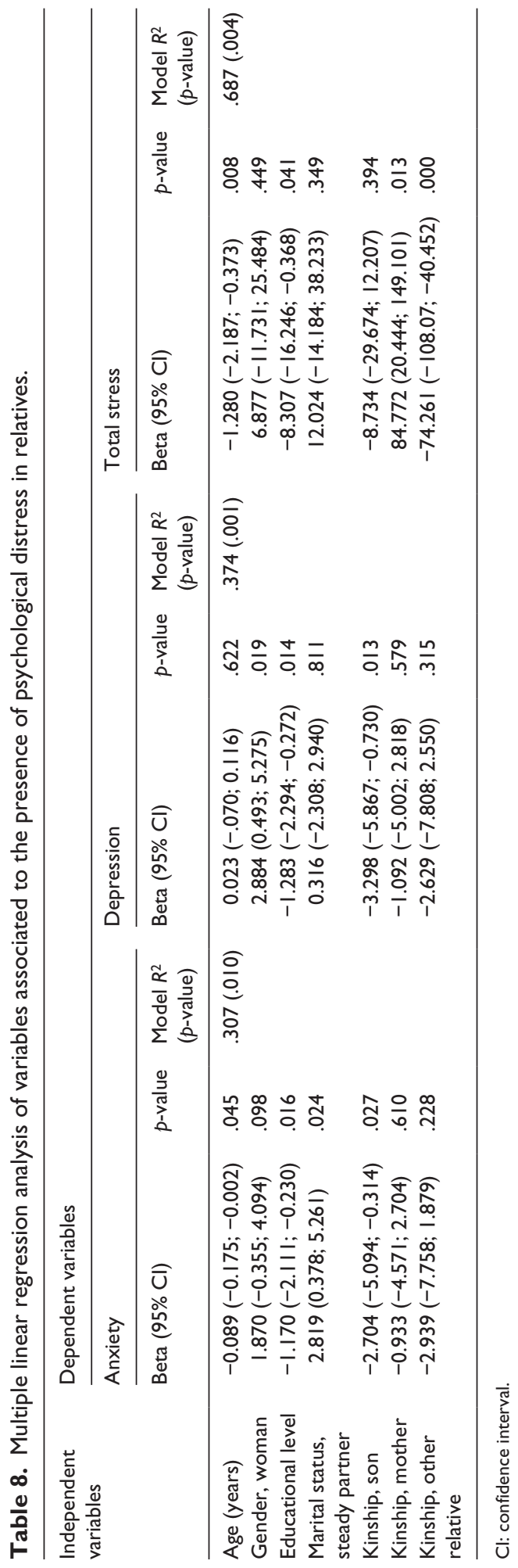


in this context. Related to the place of residence, anxiety and depression mean scores are also higher in relatives who live far from the hospital-differences have been statistically significant in state-anxiety and -depression assessed by the BDI. In this regard, not living near to the hospital entails greater psychological distress because of different factors such as not being able to be close to the patient and to find balance between taking care of the patient and another family member or such other activity as work. Analyzing differences in anxiety and depression by have or not having offspring, the results show a tendency to experience more symptoms among relatives with offspring. However, we find that the key is not having or not offspring but the son's/daughter' developmental stage and their level of dependence on parents. Considering the age, we found a significant positive correlation with depression, which is consistent with previous data (Kao et al., 2016). In our study, older relatives would correspond to middle-age relatives who have lots of responsibilities which often result difficult to combine. Similarly, a significant correlation was found between educational level and anxiety and depression, though in this case they were negative. The lower level of education, the more symptoms of anxiety and depression appeared along with greater subjective perception of depressed mood were revealed among relatives; this finding is in line with one prior study (Kao et al., 2016).

As to stress, the experience of having a loved one in ICU is stressful for almost all relatives, with a predominance of those who consider it very stressful. These results are in line with other studies (Chui and Chan, 2007; O'Farrell et al., 2000). Relatives consider as very stressful those factors related to the severity of the patient's medical condition. These factors involve greater uncertainty and doubts in family members and generate significant levels of stress (Curtis, 1983; Johansson et al., 2005). Other important stressors for relatives have been the unexpected admission to the ICU, which is considered a risk factor for anxiety symptoms in relatives (Delva et al., 2002) and not being with his or her loved one, as other authors have also stated (Da Costa et al., 2010).

Further analysis of the stress of relatives shows no significant differences in general stress by demographic variables. Considering different stressors linked to the ICU, significant differences and relations are shown by gender, marital status, have or not having offspring, kinship, place of residence, age, and educational level.

Related to the degree of interference caused by ICU admission, an important overall interference was obtained in almost all relatives, as other authors also stated (Coulter, 1989; Hupcey and Penrod, 2000). The areas more interfered were free time and work/studies in line with a previous study (Gómez et al., 2008). Some relatives spent nearly all the day in the hospital, which interferes significantly with their free time. And, a temporary work stoppage is recommended in some relatives because of the emotional impact derived from the situation. Analyzing the differences by demographic variables, in general, statistically significant differences were only found by kinship, the partner being the most affected. Examining the rest of the areas, differences were found by gender (in social life, with more interference in women) and kinship (in all areas except in family life). It is worth noting that the partner was the most affected except in the area related to the relationship with the partner; here, the most affected were fathers. These data confirm the results obtained in a previous study (Gómez et al., 2008). Regarding the relationship with a partner, it is important to mention that fathers were the most affected and mothers the least. This interesting finding could be explained by the variety of emotional involvement, the role of each member of the family as well as by the differential way of coping according to gender as some authors state when discussing parents who grieve the loss of a child (Doka and Martin, 2010).

Finally, this study also examined the extent to which different variables could be 
associated with the psychological distress experienced by relatives in this context. Particularly, having a steady partner, being a woman, and being the mother of the critically ill patient, all of them are associated with increased risk of experiencing anxiety, depression, and stress, respectively, in the context of ICU. In this regard, not the least important is to know that some variables could act as protective factors, for instance, being younger and having a higher educational level are associated with reduced anxiety and total stress. Similarly, being the son or other relative are associated with decreased anxiety and stress, respectively.

All these provide a real landscape of the distress experienced by relatives of critically ill patients while they are still in the ICU, showing the importance of considering a holistic approach in the context of the critical care, including the wellbeing not only of patients but also of relatives, given their emotional impact and their influence in the illness process of the patients. Similarly, this study includes noteworthy information for healthcare professionals, such as risk and protective factors of experiencing anxiety, depression, and stress. Knowing and paying attention to this data could change positively the course of the suffering experienced by relatives in ICU and patients indirectly.

\section{Limitations}

One possible study limitation was the reduced representativeness of the sample since data correspond to a single ICU. It is due in part to the fact that in Spain, a psychologist is not yet included in the clinical team of ICU. Another limitation was the sample size, which has been influenced by the difficulty of collecting data in the context of ICU. This threatens the statistical power of some tests and may influence some no significant results, which may be significant with a greater sample. Moreover, this limitation could also be responsible for some discrepancies, for example, when the same variable came out significant or not depending on the evaluation instrument used. Relatives are overwhelmed by the medical severity of the patient and the many changes in their life adopting even new roles as a consequence of the admission to ICU, which considerably limits their available time. Clearly, the priority of relatives when they go to the hospital is visiting the patient and not being assessed through questionnaires.

Despite limitations, the current study demonstrates the strengths in findings and highlights the need for further research on this topic in order to develop psychological interventions that may benefit physical and emotional health in the relatives of ICU patients.

\section{Acknowledgements}

The authors thank the families of critically ill patients and the ICU professional team for their special collaboration in the present study.

\section{Declaration of Conflicting Interests}

The author(s) declared no potential conflicts of interest with respect to the research, authorship, and/or publication of this article.

\section{Funding}

The author(s) disclosed receipt of the following financial support for the research, authorship, and/or publication of this article: This work was supported by a predoctoral fellowship from the Generalitat Valenciana, Spain (BFPI/2008/129) and the Ministry of Education and Science of Spain (PSI2008-01642/ PSIC).

\section{ORCID iDs}

Beatriz Gil-Juliá (iD) https://orcid.org/0000-0001 $-9262-4280$

M Desamparados Bernat-Adell (iD https://orcid. org/0000-0001-6616-6925

\section{References}

Anderson WG, Arnold RM, Angus DC, et al. (2008) Posttraumatic stress and complicated grief in family members of patients in the intensive care unit. Journal of General Internal Medicine 23(11): 1871-1876.

Anderson WG, Arnold RM, Angus DC, et al. (2009) Passive decision-making preference is associated 
with anxiety and depression in relatives of patients in the intensive care unit. Journal of Critical Care 24: 249-254.

Beck AT, Steer RA and Carbin MG (1988) Psychometric properties of the Beck Depression Inventory: Twenty-five years of evaluation. Clinical Psychology Review 8: 77-100.

Beck AT, Ward CH, Mendelson M, et al. (1961) An inventory for measuring depression. Archives of General Psychiatry 4: 561-571.

Carlson EB, Spain DA, Muhtadie L, et al. (2015) Care and caring in the intensive care unit: Family members' distress and perceptions about staff skills, communication, and emotional support. Journal of Critical Care 30: 557-561.

Choi JY, Hoffman LA, Schulz R, et al. (2013) Health risk behaviors in family caregivers during patients' stay in intensive care units: A pilot analysis. American Journal of Critical Care 2241: 45.

Chui WYY and Chan SWC (2007) Stress and coping of Hong Kong Chinese family members during a critical illness. Journal of Clinical Nursing 16: 372-381.

Cohen J (1988) Statistical Power Analysis for the Behavioral Sciences. Mahwah, NJ: Lawrence Erlbaum.

Coulter MA (1989) The needs of the family members of patients in intensive care units. Intensive Care Nursing 5: 4-10.

Curtis NM (1983) Caring for Families during the "Unknown" period. Dimensions of Critical Care Nursing 2: 248-254.

Da Costa JB, Felicetti CR, de Macedo CRL, et al. (2010) Fatoresestressantes para familiares de pacientes criticamente enfermos de umaunidade de terapia intensiva. Jornal Brasileiro De Psiquiatria 59: 182-189.

Delva D, Vanoost S, Bijttebier P, et al. (2002) Needs and feelings of anxiety of relatives of patients hospitalized in intensive care units: Implications for social work. Social Work in Health Care 35: 21-40.

Doka KJ and Martin TL (2010) Grieving Beyond Gender. Understanding the Ways Men and Women Mourn. New York: Routledge.

Echeburúa E and Corral P (1987) Escala de Inadaptación [Inadaptationscale]. Unpublished manuscript.

Echeburúa E, Corral $\mathrm{P}$ and Fernández-Montalvo J (2000) Escala de In-adaptación: Propiedades psicométricas en contextos clínicos
[Inadaptationscale: Psychometric features in a clinical setting]. Análisis Y Modificación De Conducta 26: 325-340.

Fumis RRL and Deheinzelin D (2009) Family members of critically ill cancer patients: Assessing the symptoms of anxiety and depression. Intensive Care Medicine 35: 899-902.

Fumis RRL, Ranzani OT, Faria PP, et al. (2015a) Anxiety, depression, and satisfaction in close relatives of patients in an open visiting policy intensive care unit in Brazil. Journal of Critical Care 30: 440.e1-440.e6.

Fumis RRL, Ranzani OT, Martins PS, et al. (2015b) Emotional disorders in pairs of patients and their family members during and after ICU stay. PLoS ONE 10(1): e 0115332.

Gil B, Ballester R, Gómez S, et al. (2009) Síntomas de ansiedad y depresión tras la hospitalización en una Unidad de Cuidados Intensivos. Fórum De Recerca 15: 293-304.

Gómez S, Gil B and Ballester R (2008) Grado de interferencia en los familiares de pacientes ingresados en una unidad de cuidados intensivos. Fórum De Recerca 14: 2-10.

Gómez-Carretero P, Monsalve V, Soriano JF, et al. (2009) Satisfacción con la Información: Posible Variable Interviniente en el Estado de Ánimo de Cuidadores Primarios de Pacientes Críticos. Cínica Y Salud 20: 91-105.

Herrero MJ, Blanch J, Peri JM, et al. (2003) A validation study of the hospital anxiety and depression scale (HADS) in a Spanish population. General Hospital Psychiatry 25: 277-283.

Hinkle JL and Fitzpatrick E (2011) Needs of American relatives of intensive care patients: Perceptions of relatives, physicians and nurses. Intensive \& Critical Care Nursing 27: 218-225.

Hughes F, Bryan K and Robbins I (2005) Relatives' experiences of critical care. Nursing in Critical Care 10: 23-30.

Hupcey JE and Penrod J (2000) Going it alone: The experiences of spouses of critically ill patients. Dimensions of Critical Care Nursing 19: 44-49.

Hwang DY, Yagoda D, Perrey HM, et al. (2014) Anxiety and depression symptoms among families of adult intensive care unit survivors immediately following brief length of stay. Journal of Critical Care 29; 278-282.

Johansson I, Fridlund B and Hildingh C (2005) What is supportive when an adult next-of-kin is in critical care? Nursing in Critical Care 10: 289-298. 
Kao YY, Chen CI, Chen FJ, et al. (2016) Effects of resourcefulness on sleep disturbances, anxiety, and depressive symptoms in family members of intensive care unit patients. Archives of Psychiatric Nursing 30: 607-613.

Lasa L, Ayuso-Mateos JL, Vázquez-Barquero JL, et al. (2000) The use of the beck depression Inventory to screen for depression in the general population: A preliminary analysis. Journal of Affective Disorders 57: 261-265.

Leahy JM (1992) A comparison of depression in women bereaved of a spouse, child, or a parent. Omega-Journal of Death and Dying 26: 207-217.

López S, Pastor MA, Rodríguez J, et al. (1990) Evaluación del estrés del paciente quirúrgico. Revista De Psicología De La Salud 2: 113-126.

McAdam JL and Puntillo K (2009) Symptoms experienced by family members of patients in intensive care units. American Journal of Critical Care 18: 200-209.

Maruiti MR, Galdeano LE and Farah OGD (2008) Anxiety and depressions in relatives of patients admitted in intensive care units. Actapaulista De Enfermagem 21: 636-642.

Michopoulos I, Douzenis A, Kalkavoura C, et al. (2008) Hospital Anxiety and Depression Scale (HADS): Validation in a Greek general hospital sample. Annals of General Psychiatry 7: 4.

Mitchell ML, Courtney M and Coyer F (2003) Understanding uncertainty and minimizing families' anxiety at the time of transfer from intensive care. Nursing and Health Sciences 5: 207-217.

O'Farrell P, Murray J and Hotz S (2000) Psychological distress among spouses of patients undergoing cardiac rehabilitation. Heart Lung 29: 97-104.

Paul F and Rattray J (2008) Short- and long-term impact of critical illness on relatives: Literature review. Journal of Advanced Nursing 62: 276-292.

Pochard F, Azoulay E, Chevret S, et al. (2001) Symptoms of anxiety and depression in family members of intensive care unit patients: Ethical hypothesis regarding decision-making capacity. Critical Care Medicine 29: 1893-1897.

Pochard F, Darmon M, Fassier T, et al. (2005) Symptoms of anxiety and depression in family members of intensive care unit patients before discharge or death. A prospective multicenter study. Journal of Critical Care 20: 90-96.

Quintana JM, Padierna A, Esteban C, et al. (2003) Evaluation of the psychometric characteristics of the Spanish Version of the Hospital Anxiety and Depression Scale. Acta Psychiatrica Scandinavica 107: 216-221.

Richart M, Cabrero J and Reig A(1993) Hospitalización y estrés en el paciente: Percepción diferencial de estresores entre paciente y personal de enfermería. Análisis Y Modificación De Conducta 19: $75-89$.

Sanz J and Vázquez C (1998) Fiabilidad, validez y datos normativos del Inventario para la Depresión de Beck. Psicothema 10: 303-318.

Spielberger CD, Gorsuch RL and Lushene R (1983) Manual for the State-Trait Anxiety Inventory. Palo Alto, CA: Consulting Psychologists Press.

Stroebe M, Hansson R and Schut H (2008) Handbook of Bereavement Research and Practice: Advances in Theory and Intervention. Washington, DC: American Psychological Association.

Tejero A, Guimerá EM, Farré JM, et al. (1986) Uso clínico del HADS (Hospital Anxiety and Depression Scale) en población psiquiátrica: un estudio de su sensibilidad, fiabilidad y validez. Revista Departamento Psiquiatría Facultad De Medicina De Barcelona 13: 233-238.

Terol MC, López-Roig S, Rodríguez-Marín J, et al. (2007) Propiedades psicométricas de la Escala Hospitalaria de Ansiedad y Estrés (HAD) en población española. Ansiedad Y Estrés 13: 163-176.

Turner-Cobb JM, Smith PC, Ramchandani P, et al. (2016) The acute psychobiological impact of the intensive care experience on relatives. Psychology, Health \& Medicine 21(1): 20-26.

Van Horn E and Tesh A (2000) The effect of critical care hospitalization on family members: Stress and responses. Dimensions of Critical Care Nursing 19: 40-49.

Vandall-Walker V and Clark AM (2011) It starts with access! A grounded theory of family members working to get through critical illness. Journal of Family Nursing 17: 148-181.

Vandall-Walker V, Jensen L and Oberle K (2007) Nursing support for family members of critically ill adults. Qualitative Health Research 17: 1207-1218.

Verhaeghe S, Defloor T, Van Zuuren F, et al. (2005) The needs and experiences of family members of adult patients in an intensive care unit: A review of the literature. Journal of Clinical Nursing 14: 501-509. 
Volicer BJ and Bohanon MA (1975) Hospital stress rating scale. Nursing Research 24: 352-359.

Wijngaards-de Meij L, Stroebe M, Schut H, et al. (2008) Parents grieving the loss of their child: Interdependence in coping. British Journal of Clinical Psychology 47: 31-42.

Wong P, Liamputtong P, Koch S, et al. (2017) Barriers to regaining control within a constructivist grounded theory of family resilience in ICU: Living with uncertainty. Journal of Clinical Nursing 26(23-24): 4390-4403.

Zigmond AS and Snaith RP (1983) The Hospital Anxiety and Depression Scale. Acta Psychiatrica Scandinavica 67: 361-370.

Zisook S and Shuchter SR (1991) Depression through the first year after the death of a spouse. The American Journal of Psychiatry 148: 1346-1352. 